\title{
NUMERICAL INVESTIGATION ON THE EFFECTS OF GASOLINE AND HYDROGEN BLENDS ON SI ENGINE COMBUSTION
}

\author{
Saugirdas Pukalskas ${ }^{1}$, Alfredas Rimkus ${ }^{2}$, Mindaugas Melaika ${ }^{3}$, \\ Zenonas Bogdanovičius ${ }^{4}$, Jonas Matijošius ${ }^{5}$ \\ Vilnius Gediminas Technical University \\ E-mail: ${ }^{1}$ saugirdas.pukalskas@ @gtu.lt, ${ }^{2}$ alfredas.rimkus@vgtu.lt, \\ ${ }^{3}$ mindaugas.melaika@vgtu.lt, ${ }^{4}$ zenonas.bogdanovicius@vgtu.lt, \\ 5jonas.matijosius@vgtu.lt
}

Received 2014-06-12, accepted 2014-09-12

Even small amount additive $(10 \ldots 15 \%$ by volume from whole air amount) of hydrogen $\left(\mathrm{H}_{2}\right)$ into spark ignition (SI) engines obviously effects ecological parameters and engine efficiency because of $\mathrm{H}_{2}$ exclusive properties.

SI engine work process simulation was made using AVL Boost simulation software. Analysis of results showed that engine power depends a lot on $\mathrm{H}_{2}$ supply technique into engine; $\mathrm{NO}_{\mathrm{x}}$ amount in exhaust gases directly proportional to the amount of $\mathrm{H}_{2}$, however, making mixture leaner up to $\lambda=1.6$, it is possible to reach significant $\mathrm{NO}_{\mathrm{x}}$ decrease. Increased amount of $\mathrm{H}_{2}$ as an additive in fuel, changes $\mathrm{H} / \mathrm{C}$ ratio in fuel mixture, also hydrogen improves properties of the mixture (particularly lean) and combustion of hydrocarbons what can be a reason of decreased HC emissions in exhaust gases.

Hydrogen and gasoline mixture, engine efficiency, exhaust gases, nitrous oxides, hydrocarbons, simulation.

\section{Introduction}

The most common method of energy production in the world is the burning of fossil fuels (oil products, natural gas, and coal). Large amounts of energy, which is currently very intensively used by humankind for their own needs, accumulated in these raw materials in the form of carbon and hydrogen many thousand years ago. However, the fuel combustion products $\mathrm{CO}, \mathrm{CO}_{2}, \mathrm{SO}_{\mathrm{x}}, \mathrm{NO}_{\mathrm{x}}, \mathrm{HC}$, solid particles, etc., pose serious environmental problems. Therefore, the search for alternative energy "accumulators" is the main goal of the whole mankind.

Hydrogen is carbon-free, renewable, easy (relatively) derived alternative energy "accumulator", which can be easily adapted for usage in internal combustion engines. The usage of pure hydrogen is characterized by some drawbacks because of its extremely low density, e.g., decrease in engine power, torque and coefficient of performance at low engine speed (Kahraman et al., 2006). However, enrichment of conventional fuel with hydrogen helps to avoid the aforementioned drawbacks. 
Hydrogen flame propagation speed is approximately 5 times higher than the one of other known hydrocarbon fuels (Table 1). Mixture combustion range is extremely wide, therefore, even a very small additive of hydrogen into liquid or gaseous hydrocarbon fuel can significantly expand the ignition limits of these mixtures (Rimkus, 2013). Hydrogen additive reduces the induction period and improves the period of flame propagation ( $\mathrm{Ji}$, Wang, 2011). 3\% of hydrogen (by volume) increases flame propagation speed from $11.08 \mathrm{~m} / \mathrm{s}$ (standard engine) to $15.2 \mathrm{~m} / \mathrm{s}(37 \%)$, while $6 \%$ of hydrogen - up to $17.78 \mathrm{~m} / \mathrm{s}(60 \%)$ (Ji et al., 2013). Under high air excess, even a small amount of $\mathrm{H}_{2}$ (up to $2 \%$ by volume) accelerates and improves combustion, which results in improvement of process efficiency, however, due to intensified heat release (peak temperature) $\mathrm{NO}_{\mathrm{x}}$ concentration increases in combustion products (D'Andrea et al., 2004). However, besides already mentioned characteristics of hydrogen usage some of the previous research also mentions the reduction of $\mathrm{NO}_{\mathrm{x}}$ (Jingding et al., 1998). 8\% (by volume from total quantity of mixture) of hydrogen additive already allows to achieve that engine COP would not decrease as the mixture leans down (Ji, Wang, 2011). Meanwhile, Rimkus' (Rimkus, 2011) papers reveal that as spark ignition engine runs on leaned mixture and as $\sim 0,15 \%$ (of intake air volume) HHO (Brown gas) is supplied, indicator coefficient of performance of engine increases up to $5 \%$.

As hydrogen and air mixture combusts, due to higher flame speed and combustion rate, compared to combustion of gasoline and air (Table 1), combustion duration significantly decreases in comparison with the one of gasoline and air (Mardi et al., 2014). It is also determined that as indicator pressure increases in combustion chamber, combustion temperature also grows, thus, influencing the increase of $\mathrm{NO}_{\mathrm{x}}$ emission.

Table 1. Fuel properties (Bain et al., 1998)

\begin{tabular}{|l|c|c|}
\hline \multicolumn{1}{|c|}{ Properties } & Hydrogen & Gasoline (izo-octan) \\
\hline Chemical formula & $\mathrm{H}_{2}$ & $\mathrm{C}_{8} \mathrm{H}_{18}$ \\
\hline Ignition energy, $\mathrm{mJ}$ & 0,02 & 0,24 \\
\hline Flame propagation speed, $\mathrm{cm} / \mathrm{s}$ & 237 & 41,5 \\
\hline Diffusion coefficient, $\mathrm{cm}^{2} / \mathrm{s}$ & 0,61 & 0,05 \\
\hline Higher heating value, $\mathrm{MJ} / \mathrm{kg}$ & 142 & 47,3 \\
\hline Lower heating value, $\mathrm{MJ} / \mathrm{kg}$ & 120 & 44 \\
\hline Molecular mass & 2,02 & $\approx 107 \ldots 114$ \\
\hline Octane number & 106 & 100 \\
\hline Stoichiometric ratio & 34,3 & 14,7 \\
\hline Density, $\mathrm{kg} / \mathrm{m}^{3}$ & 0,09 & 750 \\
\hline
\end{tabular}

The analysis of scientific literature resources revealed a number of experimental studies on spark engine running on different mixtures of hydrogen and various fuels, as well as a lot of modelling tests, where the combustion process of various pure fuels is modelled, however, no scientific article, modelling the combustion of gasoline and hydrogen, has been found. Therefore, the aim of this research is to develop a mathematical model of spark ignition engine running on 
gasoline and hydrogen mixture by using the simulation tool AVL Boost, and to find the main energy and environmental indicators of the engine on the basis of aforementioned model.

\section{Research methodology}

Assessment of hydrogen influence on internal combustion engine performance indicators was performed on the basis of bench tests and numerical modelling of Nissan Qashqai spark ignition engine HR 16DE (Table 2). The study was performed at constant engine speed $\left(n=2000 \mathrm{~min}^{-1}\right)$, throttle opening position (15\%) and ignition advance angle $\Theta=18^{\circ}$ before TDC. Bench tests were performed by using gasoline $(\mathrm{G})$, at air excess coefficient of $\lambda=1$. Numerical modelling was performed by using gasoline and mixtures of gasoline and hydrogen. It was accepted that there will be $10 \%$ of hydrogen $\left(\mathrm{G}+10 \% \mathrm{H}_{2}\right)$; and $15 \%$ of hydrogen $\left(\mathrm{G}+15 \% \mathrm{H}_{2}\right)$ in the intake air volume. Modelling was performed for flammable mixture of various compositions $(\lambda=0.9 \ldots 1.6)$.

Table 2. Engine Nissan HR 16 DE technical data

\begin{tabular}{|l|l|}
\hline Parameter & Value \\
\hline Number of cylinders & 4 \\
\hline Cylinder bore, $\mathrm{mm}$ & 78 \\
\hline Piston stroke, $\mathrm{mm}$ & 83.6 \\
\hline Displacement, $\mathrm{cm}^{3}$ & 1598 \\
\hline Nominal power, $\mathrm{kW}\left(\mathrm{min}^{-1}\right)$ & $84(6000)$ \\
\hline Maximum engine torque, $\mathrm{Nm}\left(\mathrm{min}^{-1}\right)$ & $156(4400)$ \\
\hline Compression ratio, $\varepsilon$ & 10.7 \\
\hline Number of valves per cylinder & 4 \\
\hline
\end{tabular}

Bench tests were performed during initial stage of the study by using test equipment of Internal Combustion Engines Laboratory of Department of Automobile Transport of Vilnius Gediminas Technical University (Fig. 1). The tested engine is controlled by programmable ECU MoTeC M800. While braking with eddy-current load stand $A M X 200 / 100$, engine's effective torque $M_{e}$ is measured. Pressure in cylinder is determined by pressure sensor $A V L Z I 31$, built-in in spark plug, and recorded by using AVL DiTEST DPM 800. Gasoline (G) hourly consumption $\left(B_{d_{-} G}\right)$ is measured by electronic fuel consumption gauge $A M X 212 F$. Exhaust emission was tested with AVL DiSmoke 4000 emission tester. 


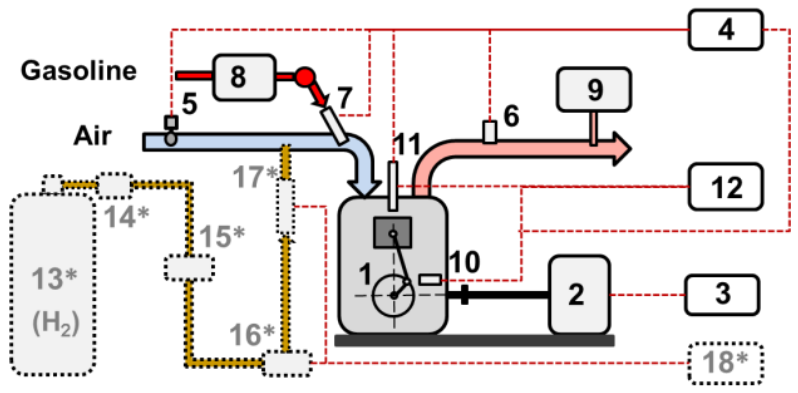

Fig. 1. Scheme of engine stand research equipment: 1 - Nissan HR $16 D E$ engine; 2 - engine load stand $A M X$ 200/100; 3 - electronic control unit of load stand; 4 - control unit of engine MoTeC M800; 5 -throttle control servomotor; 6-oxygen sensor; 7 - gasoline injector; 8 -gasoline consumption gauge $A M X 212 F ; 9$ - exhaust gas analyser AVL DiSmoke 4000; 10 - crankshaft position sensor ; 11 - spark plug with built-in pressure sensor AVL ZI31; 12 - equipment for measuring the pressure in cylinder AVL DiTEST DPM 800; 13 compressed $\mathrm{H}_{2}$ gas cylinder; 14 - high pressure reducer; 15 -gas meter; 16 - low pressure reducer; 17 - gas injector; 18 - gas equipment supply control unit; *-additional $\mathrm{H}_{2}$ gas supply equipment

Numerical modelling of engine performance was implemented with AVL Boost by creating the model of internal combustion engine, using visual icons (Fig. 2).

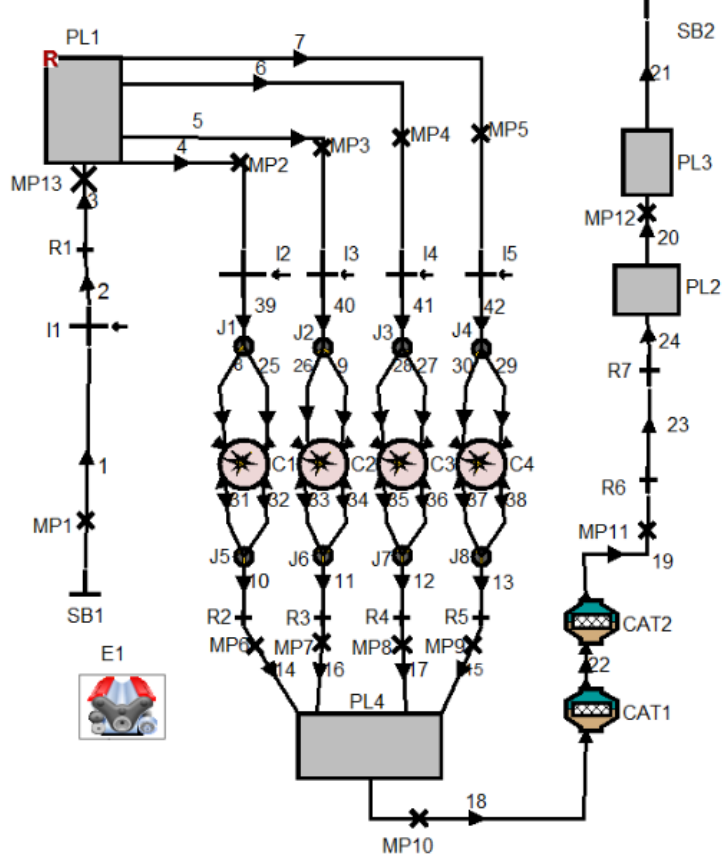

Fig. 2. Model of internal combustion engine developed by numerical modelling tool $A V L$ BOOST

During modelling, the following marginal conditions were selected: inlet air pressure, quantity, temperature; temperature, pressure of exhaust combustion 
products; quantity of injected fuel, air excess coefficient, etc. It was selected that fuel mixture (hydrogen and gasoline fuel mixture) is injected into intake manifold by four injectors.

While performing the analysis of combustion process by applying Vibe function (Vibe 1970), the characteristics of heat release of the engine are approximated:

$$
\begin{gathered}
\frac{d x}{d \varphi}=\frac{a}{\Delta \varphi_{\mathrm{c}}} \cdot\left(m_{v}+1\right) \cdot y^{m_{\nu}} \cdot e^{-a \cdot y^{\left(m_{v}+1\right)}} ; \\
d x=\frac{d Q}{Q},
\end{gathered}
$$

where $Q$ - heat released by fuel during duty cycle; $\varphi$ - crankshaft rotation angle; $m_{v}$ - combustion intensity parameter; $a$-Vibe constant at $99,9 \%$ fuel combustion; $a=6,905 ; y$ - relative combustion time:

$$
y=\frac{\varphi-\varphi_{0}}{\Delta \varphi_{c}}
$$

where $\varphi_{0}-$ start of combustion; $\Delta \varphi_{c}-$ combustion duration.

By integrating Vibe function, we calculate the part of fuel mass, which has burned down from the start of combustion process:

$$
x=\int \frac{d x}{d \varphi} \cdot d \varphi=1-e^{-a \cdot y^{\left(m_{v}+1\right)}} .
$$

A two-zone Vibe function is used for synthesis and analysis of engine duty cycle during numerical modelling. In this case, it is taken into account that the zones of burned and not burned mixture occur during combustion. By taking into account the duty regime of engine, heat release of fuel combustion, heat and gas exchange in cylinder, the analysis showed the change in gas temperature and pressure during cycle. What is more, energy and environmental indicators are calculated. Combustion duration $\left(\Delta \varphi_{c}\right)$ and combustion intensity parameter $\left(m_{v}\right)$, as the engine is running on gasoline and hydrogen mixture, is selected depending on the composition of mixture by taking into consideration the properties of fuel (Safari et al., 2009).

\section{Results and their analysis}

The intake air volume, determined during bench tests, as the engine was running on gasoline $\left(n=2000 \mathrm{~min}^{-1}\right.$, throttle $15 \%, \Theta=18^{\circ}$ and $\left.\lambda=1\right)$, is $40.70 \mathrm{~m}^{3} / \mathrm{h}$. It is assumed that this intake gas volume remains constant as the engine intakes air and hydrogen gas mixture: $V=V_{\text {air }}+V_{H 2}=$ const. $=40.70 \mathrm{~m}^{3} / \mathrm{h}$. 
As $10 \% \mathrm{H}_{2}$ is supplied to air, it makes $V_{\mathrm{H} 2}=4.07 \mathrm{~m}^{3} / \mathrm{h}$, and $15 \% \mathrm{H}_{2}$ hydrogen will take $V_{H 2}=6.10 \mathrm{~m}^{3} / \mathrm{h}$, respectively, therefore, intake air quantity will decrease down to $V_{\text {air }}=36.64 \mathrm{~m}^{3} / \mathrm{h}$ and $V_{\text {air }}=34.60 \mathrm{~m}^{3} / \mathrm{h}$, respectively. While leaning the mixture from $\lambda=0.9$ to $\lambda=1.6$, an increasingly higher air quantity (according to the determined air excess coefficient) will be required for hydrogen combustion. The air quantity unused for $\mathrm{H}_{2}$ combustion will decrease, and, taking into account the remaining air and $\lambda$, the mass of injected gasoline is calculated. While leaning the mixture within the set limits at constant $\mathrm{H}_{2}$ supply and as gasoline quantity decreases, hydrogen mass concentration grows from $12 \%$ to $24 \%$ $\left(\mathrm{G}+10 \% \mathrm{H}_{2}\right)$ and from $21 \%$ to $47 \%\left(\mathrm{G}+15 \% \mathrm{H}_{2}\right)$ (Fig. 3).

Despite the fact that lower calorific value of hydrogen $\left(H_{l_{-} H 2}=120 \mathrm{MJ} / \mathrm{kg}\right)$ is 2.76 times higher than the one of gasoline $\left(H_{l_{-} G}=43.5 \mathrm{MJ} / \mathrm{kg}\right)$, as $\mathrm{H}_{2}$ is additionally supplied in case of stoichiometric mixture, the energy brought by fuel decreases from $155.73 \mathrm{MJ} / \mathrm{h}(\mathrm{G}) 5.8 \%\left(\mathrm{G}+10 \% \mathrm{H}_{2}\right)$ and $8.7 \%\left(\mathrm{G}+15 \% \mathrm{H}_{2}\right)($ Fig. 4).

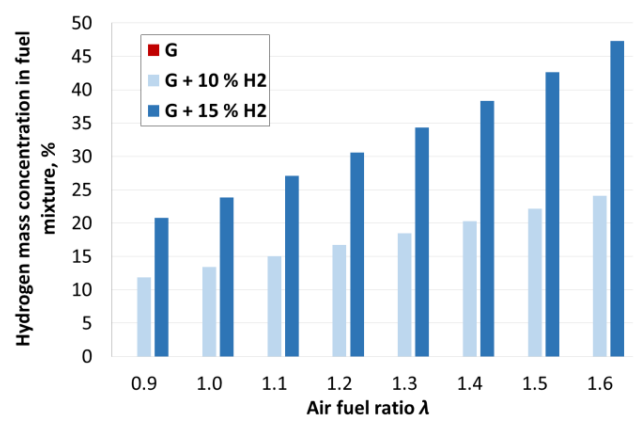

Fig. 3. Dependence of hydrogen mass concentration in fuel mixture on hydrogen concentration and excess coefficient

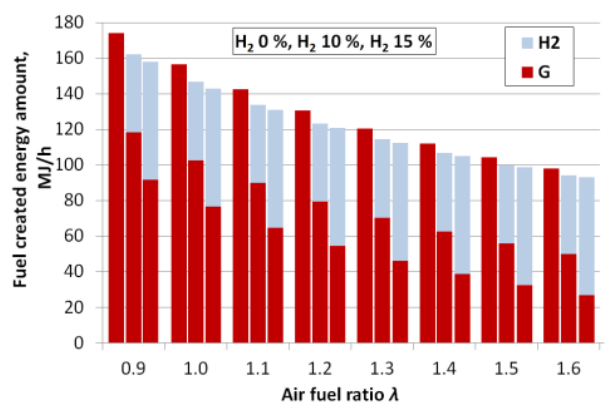

Fig. 4. Dependence of energy quantity brought by hydrogen $\left(\mathrm{H}_{2}\right)$ and gasoline (G) on hydrogen concentration and air excess coefficient

When leaning mixture, the energy brought by fuel decreases significantly, since as a result of decrease of quantity of air for gasoline, there is a decrease of injected gasoline mass, as well as in its energy. At $\lambda=1.6$, the energy brought by gasoline decreases down to $97.33 \mathrm{MJ} / \mathrm{h}$ (37.5\%). Additional supply of $\mathrm{H}_{2}$ decreases the energy of fuel mixture by $3.3 \%\left(\mathrm{G}+10 \% \mathrm{H}_{2}\right)$ and $4.9 \%\left(\mathrm{G}+15 \% \mathrm{H}_{2}\right)$.

The effective power of the engine, determined during bench tests, as the engine was running on gasoline and under stoichiometric mixture, was $P_{e}=11.91 \mathrm{~kW}$. After performing the analysis of engine duty cycle and following the scientific literature resources (Safari et al., 2009; Rakopoulos et al., 2010), combustion duration $\Delta \varphi_{c}=47$ and combustion intensity parameter $m_{v}=2.5$ was found. By using the aforementioned indicators and upon performing the analysis of combustion process, the determined effective power of the engine $P_{e}=12.07 \mathrm{~kW}$ differs from the measured one only by $1.3 \%$, and it means that the created numerical model is quite accurate. During numerical modelling, as hydrogen concentration in mixture varied and composition of combustible mixture was 
changed, the parameters were selected by taking into account the fact that hydrogen increases combustion intensity and accelerate flame front propagation speed, and combustion intensity decreases in case of leaning the mixture (Heywood, 1988).

Numerical modelling revealed that in case of stoichiometric mixture and additional supply of $10 \% \mathrm{H}_{2}$, engine power decreases by $9.5 \%$ (from $12.07 \mathrm{~kW}$ to $10.92 \mathrm{~kW}$ ), and in case of supply of $15 \% \mathrm{H}_{2}-15.5 \%$ (from $12.07 \mathrm{~kW}$ to $10.2 \mathrm{~kW}$ ) (Fig. 5). The estimated decrease in power is higher than the determined decrease in energy, brought by fuel, while supplying $\mathrm{H}_{2}$ gas, since hydrogen changes combustion parameters, and the identified ignition advance angle $\Theta=18^{\circ}$ is not optimal. It is also confirmed by decrease of indicator coefficient of performance $\eta_{i}$ (Fig. 6) from $0.351(\mathrm{G})$ to $0.334(-4.8 \%)\left(\mathrm{G}+10 \% \mathrm{H}_{2}\right)$ and to $0.327(-6.8 \%)$ $\left(\mathrm{G}+15 \% \mathrm{H}_{2}\right)$.

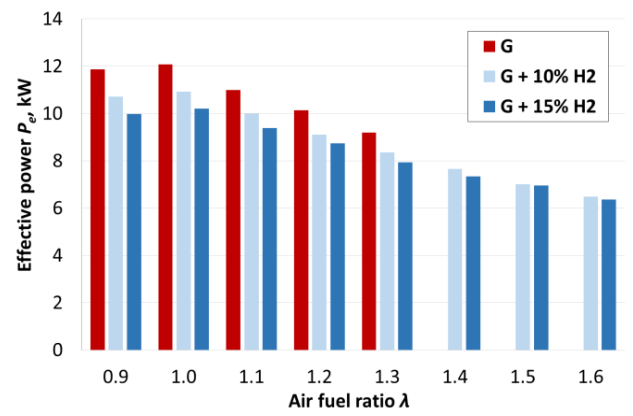

Fig. 5. Dependence of effective power on hydrogen concentration and air excess coefficient

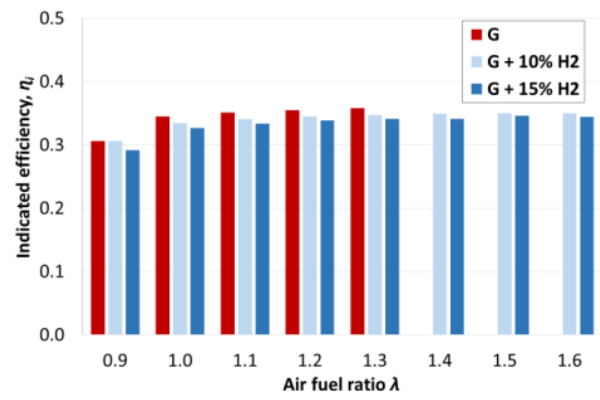

Fig. 6. Dependence of indicator coefficient of performance on hydrogen concentration and air excess coefficient

While leaning the mixture, engine power decreases. In case of engine, running on pure gasoline, $\lambda=1.3$ is the ignition threshold, i.e., spark plug does not ignite leaner mixtures of gasoline and air. However, significantly leaner gasoline and hydrogen mixtures can be ignited. Following numerical modelling, it was found that in case of hydrogen supply, engine power is $6.46 \mathrm{~kW}\left(\mathrm{G}+10 \% \mathrm{H}_{2}\right)$ and $6.36 \mathrm{~kW}\left(\mathrm{G}+15 \% \mathrm{H}_{2}\right)$.Indicator coefficient of performance is equal to 0.350 and 0.344 , respectively. Energy efficiency of the engine in case of lean mixture $(\lambda=1.6)$ and additional supply of $10 \% \mathrm{H}_{2}$ is close to the one as in case of using stoichiometric mixture of gasoline - air, however, environmental indicators of the engine significantly improve (Fig. 9 and 10). In case of richer mixture $(\lambda=0.9)$, energy and environmental indicators of the engine worsen because of the lack of oxygen, required for combustion, and too early start of combustion. 


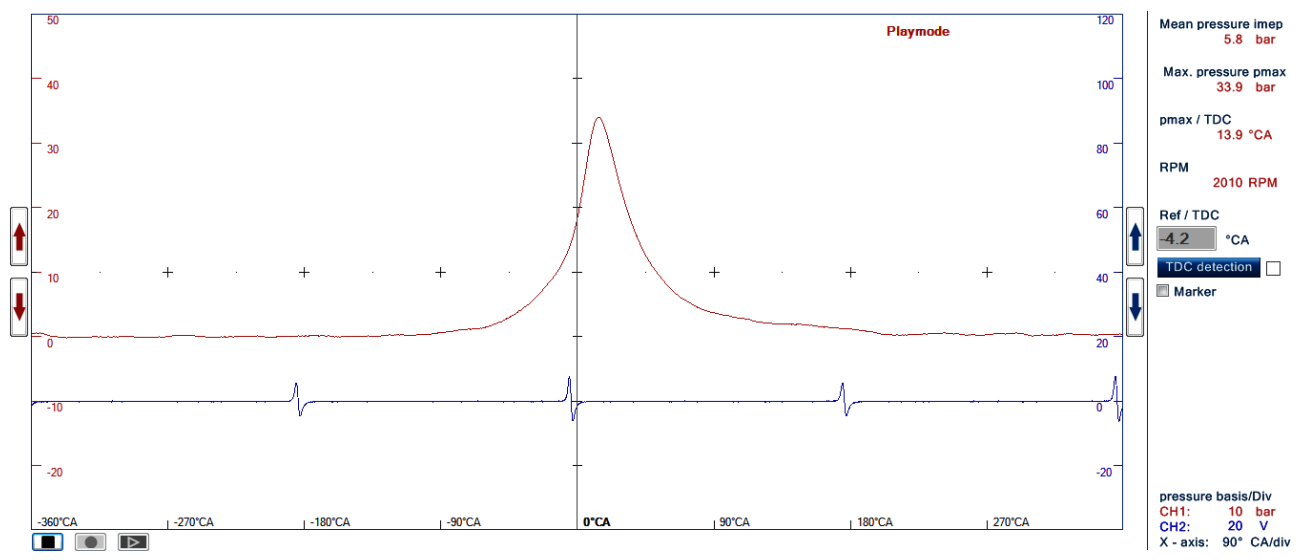

Fig. 7 Pressure in cylinder determined by stand experiments

Pressure in engine cylinder, measured during bench tests, as the engine was running on stoichiometric mixture, reaches $p_{\max }=3.39 \mathrm{MPa}$, as crankshaft turns at $13.9^{\circ}$ after TDC (Fig. 7.). Numerical modelling resulted in close indicators $p_{\max }=3.50 \mathrm{MPa}$ at $13.6^{\circ}$ after TDC. This confirms the properly set modelling parameters.

The maximum values of pressure $p_{\max }$ and temperature $T_{\max }$, obtained after making calculations for the provided combustible mixtures, are given in Figure 8. As hydrogen concentration is increased in mixture, combustion takes place more intensively, and the maximum pressure and temperature reached is closer to TDC $\left(\varphi_{\text {pmax }}\right.$ and $\left.\varphi_{\text {Tmax }}\right)$. However, in case of leaning the mixture, combustion intensity decreases and approaches to optimum set ignition advance angle. Thus, by additional supply of hydrogen and by leaning the combustible mixture, it is possible to obtain the optimum indicator coefficient of performance for a cycle without additional adjustment of combustion start. However, it is lower than in case of engine running on gasoline, since larger part of thermal energy is transferred to environment due to higher combustion temperature of hydrogen.

It was determined that in case of additional supply of hydrogen and increase of its quantity, there is an increase of $\mathrm{NO}_{\mathrm{x}}$ concentration in exhaust gas (Fig. 9). It is mostly affected by free quantity of oxygen (excess air) during combustion, combustion intensity, and maximum temperature. In comparison with pure gasoline, hydrogen additive mostly increases $\mathrm{NO}_{\mathrm{x}}$ concentration (up to $60 . . .70 \%$ ) at $\lambda=1.1 \ldots 1.3$. However, by comparing the emission of nitrogen oxides as engine runs on gasoline $(\lambda=1)$ with emission as engine runs on $\mathrm{G}+10 \% \mathrm{H}_{2}$ mixture $(\lambda=1.6)$, the concentration of pollutants decreases $96 \%$, when the power goes down only $46 \%$. 

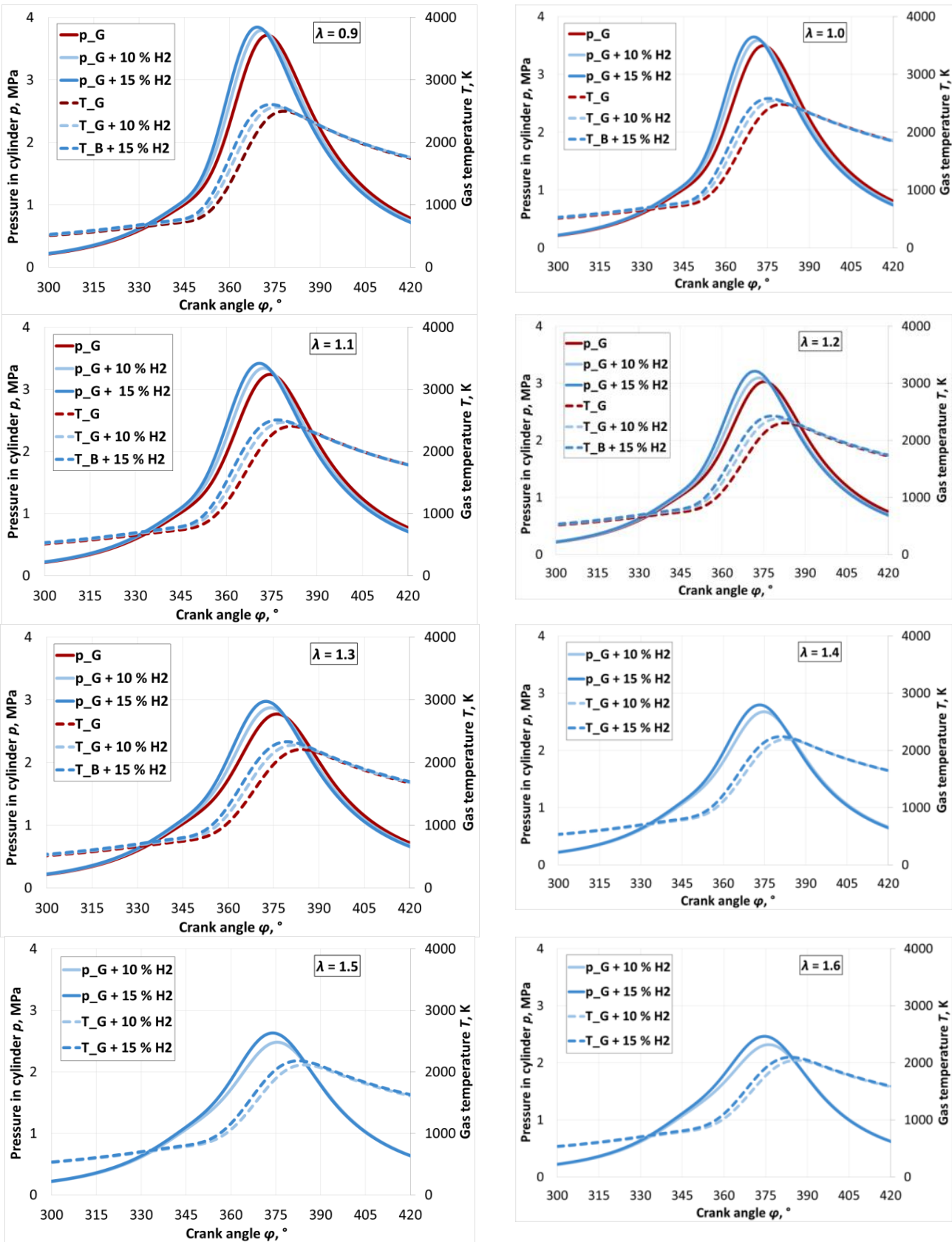

Fig. 8. Dependence of gas pressure $(p)$ and temperature $(T)$ in cylinder on hydrogen concentration and air excess coefficient 


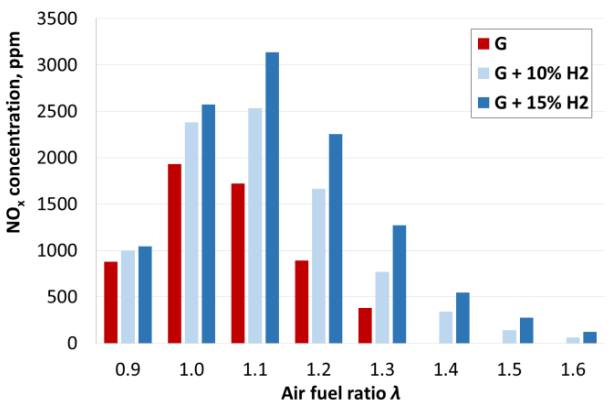

Fig. 9. Dependence of nitrogen oxide concentration in combustion products on hydrogen concentration and air excess coefficient

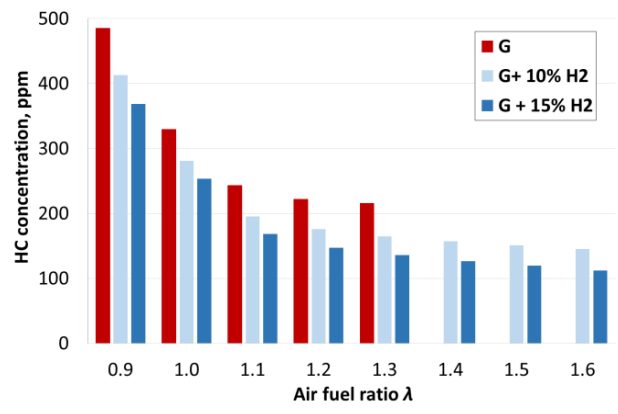

Fig. 10. Dependence of hydrocarbon concentration in combustion products on hydrogen concentration and air excess coefficient

Hydrocarbon concentration in exhaust gases decreases, when leaning the mixture and increasing the concentration of additionally supplied hydrogen (Fig. 10). The mixture with hydrogen can combust even at high air excess $(\lambda=9.85)$, it is characterized by high diffusion (Gupta, 2009). Furthermore, it increases combustion and temperature and, thus, improves oxidation of hydrocarbons. $10 \%$ of hydrogen, according to volume in intake air, at different richness of combustible mixture, reduces $\mathrm{HC}$ concentration by $15 \ldots 28 \%, 15 \%$ of hydrogen reduces $\mathrm{HC}$ by $23 . . .44 \%$. By comparing the hydrocarbon emission as engine runs on gasoline $(\lambda=1)$ with emission as engine runs on $\mathrm{G}+10 \% \mathrm{H}_{2}$ mixture $(\lambda=1.6)$, the concentration of pollutants decreases $56 \%$.

\section{Conclusions}

The completed complex experimental and numerical modelling studies of spark ignition engines, as well as analysis of changes of their performance indicators, while using gasoline and the mixture of gasoline and hydrogen fuels, enabled to present the following conclusions on influence of hydrogen gas on energy and environmental indicators of internal combustion engines:

1. Hydrogen, additionally supplied to intake manifold, occupies a certain volume, thus, reducing cylinder filling with air and, in turn, results in decrease of engine power.

2. As hydrogen concentration in combustible mixture increases, intensity and duration of combustion changes, combustion process deviates from the optimum one, and this reduces indicator coefficient of performance. Thermal efficiency of the engine is also reduced by combustion temperature, increased by hydrogen, since larger part of thermal energy of fuel is transferred to environment.

3. By additional supply of hydrogen and by leaning the combustible mixture, it is possible to obtain the optimum indicator coefficient of performance for a cycle without additional adjustment of combustion start. 
4. The additive of $15 \% \mathrm{H}_{2}$ in air increases $\mathrm{NO}_{\mathrm{x}}$ concentration in exhaust gas up to $60 . . .70 \%$ at $\lambda=1.1 \ldots 1.3$. However, by comparing the emission of nitrogen oxides as engine runs on gasoline $(\lambda=1)$ with emission as engine runs on $\mathrm{G}+10 \% \mathrm{H}_{2}$ mixture $(\lambda=1.6)$, the concentration of pollutants decreases $96 \%$, when the power goes down only $46 \%$.

5. Hydrogen improves hydrocarbon combustion. $10 \%$ of hydrogen, according to volume in intake air, in comparison with pure gasoline at $\lambda=1.1 \ldots 1.6$, reduces $\mathrm{HC}$ concentration by $15 \ldots 28 \%, 15 \%$ of hydrogen reduces $\mathrm{HC}$ by $23 . . .44 \%$.

\section{Acknowledgement}

This work has been supported by the European Social Fund within the project "Development and application of innovative research methods and solutions for traffic structures, vehicles and their flows", project code VP1-3.1ŠMM-08-K-01-020.

The results of the research, described in the article, were obtained by using a virtual internal engine simulation tool $A V L$ BOOST, acquired by signing the Cooperation Agreement between AVL Advanced Simulation Technologies and Faculty of Transport Engineering of Vilnius Gediminas Technical University.

\section{References}

1. Bain, A.; Barclay, J.; Bose, T.; Edeskuty, F.; Fairlie, M.; Hansel, J.; Hay, D.; Swain, M. 1998. Sourcebook for Hydrogen Applications. Montreal: TISEC Inc.

2. D'Andrea, T.; Henshaw, P. F.; Ting, D. S.-K. 2004. The addition of hydrogen to a gasoline-fuelled SI engine. International Journal of Hydrogen Energy, 29, 1541 - 1552. DOI:10.1016/j.ijhydene.2004.02.002

3. Gupta, R., B. 2009. Hydrogen fuel: production, transport, and storage. Boca Raton: Taylor \& Francis Group, CRC Press.

4. Heywood, J., B. 1988. Internal combustion engine fundamentals. 1st ed. New York: McGraw-Hill.

5. Ji, Ch.; Liu, X.; Gao, B.; Wang, Sh.; Yang, J. 2013. Numerical investigation on the combustion process in a spark-ignited engine fueled with hydrogen-gasoline blends. International journal of hydrogen energy, 38, 11149 11155. DOI:10.1016/j.ijhydene.2013.03.028.

6. Ji, Ch.; Wang, Sh. 2011. Effect of hydrogen addition on lean burn performance of a spark-ignited gasoline engine at $800 \mathrm{rpm}$ and low loads. Fuel, 90, 1301-1304. DOI:10.1016/j.fuel.2010.11.014.

7. Jingding, L.; Linsong, G.; Tianshen, D. 1998. Formation and restraint of toxic emissions in hydrogen-gasoline mixture fueled engines. Int $J$ Hydrogen Energy, 23(10), 971-975.

8. Kahraman, E.; Ozcanlıb, S., C.; Ozerdem, B. 2006. An experimental study on performance and emission characteristics of a hydrogen fuelled spark ignition engine. International Journal of Hydrogen Energy, 32, 2066-2072. DOI:10.1016/j.ijhydene.2006.08.023 
9. Mardi, K. M.; Khalilarya, Sh.; Nemati, A. 2014. A numerical investigation on the influence of EGR in a supercharged SI engine fueled with gasoline and alternative fuels. Energy Conversion and Management, 83, 260-269. DOI: 10.1016/j.enconman.2014.03.031

10.Rakopoulos, C., D.; Kosmadakis, G., M.; Pariotis, E., G. 2010. Evaluation of a combustion model for the simulation of hydrogen spark-ignition engines using a CFD code. International journal of hydrogen energy, 35, 1254512560. DOI: 10.1016/j.ijhydene.2010.09.002

11.Rimkus, A. 2013. Improvement of efficiency of operation of an internal combustion engine by using Brown gas. Dissertation Thesis (03T), Vilnius Gediminas Technical University.

12.Rimkus, A.; Pukalskas, S.; Matijošius, J. 2011. The research on efficiency of using HHO gas (oxyhydrogen) in petrol internal combustion engines [CD]. In: International conference on hydrogen production (ICH2P-11), June 2011, Thessaloniki, Greece.

13.Safari, H.; Jazayeri, S., A.; Ebrahimi, R. 2009. Potentials of $\mathrm{NO}_{\mathrm{x}}$ emission reduction methods in SI hydrogen engines: Simulation study. International journal of hydrogen energy, 34, 1015-1025. DOI: 10.1016/j.ijhydene.2008.10.029

14.Vibe, I., I. 1970. Brennverlauf und Kreisprozeß von Verbrennungsmotoren. Berlin: Verlag Technik. 